\title{
Decrease of fear avoidance beliefs following person-centered progressive resistance exercise contributes to reduced pain disability in women with fibromyalgia: secondary exploratory analyses from a randomized controlled trial
}

Annie Palstam ${ }^{1 *}$, Anette Larsson ${ }^{1,2}$, Monika Löfgren ${ }^{3}$, Malin Ernberg ${ }^{4}$, Jan Bjersing ${ }^{5}$, Indre Bileviciute-Ljungar ${ }^{3}$, Björn Gerdle ${ }^{6,7}$, Eva Kosek ${ }^{8}$ and Kaisa Mannerkorpi ${ }^{1,2}$

\begin{abstract}
Background: Fibromyalgia (FM) is characterized by persistent widespread pain, increased pain sensitivity and tenderness. Women with FM also report disability, in terms of negative consequences on activities of daily living. Our recent randomized controlled trial $(\mathrm{RCT})$ is the first study of resistance exercise to show positive effects on pain disability. The resistance exercise program of our RCT emphasized active involvement of participants in planning and progression of the exercise, using the principles of person-centeredness, to support each participant's ability to manage the exercise and the progress of it. The aim of this sub-study was to investigate explanatory factors for reduced pain disability in women with FM participating in a 15-week person-centered progressive resistance exercise program.

Methods: A total of 67 women with FM were included in this sub-study of an RCT examining the effects of person-centered progressive resistance exercise performed twice a week for 15 weeks. Tests of physical capacity and health-related questionnaires were assessed at baseline and after the intervention period. Multivariable stepwise regression was used to analyze explanatory factors for improvements in pain disability.

Results: Reduced pain disability was explained by higher pain disability at baseline together with decreased fear avoidance beliefs about physical activity $\left(R^{2}=28, p=0.005\right)$. The improvements in the disability domains of recreation and social activity were explained by decreased fear avoidance beliefs about physical activity together with higher baseline values of each disability domain respectively $\left(R^{2}=32, p=0.025\right.$ and $\left.R^{2}=30, p=0.017\right)$. The improvement in occupational disability was explained by higher baseline values of occupational disability $\left(R^{2}=19\right.$, $p=0.001)$.

\footnotetext{
* Correspondence: annie.palstam@gu.se

${ }^{1}$ Institute of neuroscience and physiology, Sahlgrenska Academy, University

of Gothenburg, Gothenburg, Sweden

Full list of author information is available at the end of the article
} 
(Continued from previous page)

Conclusion: The person-centered resistance exercise intervention, based on principles of self-efficacy, had a positive effect on recreational, social and occupational disability. The reduced pain disability seemed to be mediated by decreased fear avoidance beliefs. Age, symptom duration, pain intensity, and muscle strength at baseline had no explanatory value for reduced pain disability, indicating that the person-centered resistance exercise program has the potential to work for anyone with FM who has interest in physical exercise.

The trial was registered on October 21, 2010 with ClinicalTrials.gov identification number: NCT01226784.

Keywords: Fibromyalgia, Pain, Disability, Resistance exercise, Person-centered

\section{Background}

Disability is a complex concept that includes impairment, activity limitation, and participation restriction, reflecting the bio-psychosocial interaction between the person and the context in which he or she lives [1]. Musculoskeletal disorders are one of the most common reasons for work disability and sick leave in Sweden [2, 3] and hence, entail large costs for the individual and for society [4-6]. Fibromyalgia (FM) affects approximately $1-3 \%$ of the general population, is more prevalent in older age $[7,8]$ and is six times more common in women than in men [9]. Women with FM are challenged by chronic pain, fatigue, psychological distress [10], and impaired physical capacity [11-14], and report consequences on their activities of daily life and difficulties in fulfilling their life roles $[15,16]$, including their ability to work $[14,17-20]$. Reduced physical capacity and pain in FM appear to contribute to participation restriction and disability [14, 21]. Further, the physical demands at work constitute substantial problems for persons with musculoskeletal pain to manage their work and entail increased risks of work disability and sick leave [22, 23]. Also, women with FM describe their impaired physical capacity as being a hindrance for managing physical work demands [24].

Women with FM have been shown to be less physically active than healthy women, especially in moderate to high intensity physical activity [25]. The relationship between pain and muscle weakness in FM is not entirely understood but may to some degree be explained by exercise-induced pain [26]. Pain is an obstacle for patients to engage in exercise of higher intensity [27] and could also raise fear avoidance beliefs about physical activity that may lead to a vicious circle of inactivity and disability [28].

Individually tailored physical exercise is recommended for improving physical capacity and participation in daily life activities in FM [29-33]. Previous studies of resistance exercise in women with FM have observed improved muscle strength [34-38], and reduced pain intensity following resistance exercise [37-40]. Our recently published randomized controlled trial (RCT) is the first study of resistance exercise in FM to also show positive effects on pain disability assessed as the total score of the pain disability index (PDI) [37]. However, changes in the separate subscales assessing different domains of pain disability were not investigated. The resistance exercise program focused on the active involvement of each participant in planning and progressing the exercise program, using the principles of person-centeredness. This theory emphasizes the partnership between participant and physiotherapist and shared decision-making based upon the participant's descriptions of their wishes, needs, and resources, and this approach is suggested to support each participant's ability to manage the exercise and the progress of it, and subsequently to enhance the patient's ability to manage their health problems [41].

The factors interacting with reduced pain disability in women with FM engaging in resistance exercise have to the best of our knowledge not previously been investigated. The aim of this sub-study was to investigate explanatory factors for improvements in aspects of pain disability in women with FM, participating in a 15-week person-centered progressive resistance exercise program.

\section{Methods}

\section{Study design}

This was a sub-study of an assessor-blinded randomized controlled multi-center trial, which examined the effects of progressive resistance group exercise compared with an active control group. The trial was registered on 21 October 2010 with ClinicalTrials.gov identification number: NCT01226784 [37]. The study was approved by the regional ethics committee in Stockholm (2010/1121-31/3). Written and oral information was given to all participants and written consent was obtained from all participants.

\section{Participants}

The recruitment started in 2010 and data collection was completed at all sites (Gothenburg, Stockholm, and Linköping) in 2013. Inclusion and exclusion criteria have been described in detail previously [37]. In short, the inclusion criteria were women aged 20-65 years, meeting the American College of Rheumatology (ACR) 1990 classification criteria for FM and the exclusion criteria were other severe somatic or psychiatric disorders, 
participation in a rehabilitation program within the past year, or inability to understand Swedish. Women with FM were recruited to the multi-center experimental study by newspaper advertisement in the local newspapers of three cities in Sweden (Gothenburg, Stockholm, and Linköping) [37]. One-hundred and thirty women with FM were included in the multicenter experimental study, of whom 67 were randomized to the resistance exercise group. The process of recruitment and randomization has been described in detail in the previous publication [37]. All participants were invited to a post-treatment examination after the 15-week intervention period and $84 \%(n=56)$ of the women in the resistance exercise group completed the examination. Five participants in the resistance exercise group reported adverse effects and chose to discontinue the intervention due to increased pain. Out of these, two participants completed the post-treatment examinations [37].

\section{Resistance exercise intervention}

The person-centered progressive resistance exercise intervention was performed twice a week for 15 weeks at physiotherapy premises and at a local gym, in small groups and supervised by experienced physiotherapists. The exercise sessions started with a 10-minute warm up followed by 50 minutes of resistance exercises focusing on large muscle groups in all four extremities and trunk. The resistance exercise was initiated at low loads corresponding to $40 \%$ of one repetition maximum (RM) and progressed up to $80 \%$ of one RM during the 15 weeks. Possibilities for progressions of loads were evaluated every 3-4 weeks. Forty-two participants $(62.7 \%)$ reached exercise loads of $80 \%$ of 1 RM while seven participants $(10.4 \%)$ reached exercise loads of $60 \%$ of 1 RM. The median attendance rate at the exercise sessions was $71 \%$ (range $0-100 \%$ ). A more detailed description of the procedure of the resistance exercise and the adjustment of loads has been described previously [37].

\section{Assessments}

Outcomes were assessed at baseline and immediately after the 15-week intervention period. All participants were invited to post-treatment examinations according to an intention-to-treat design. Examinations included self-reported questionnaires, performance-based tests of muscle strength, and assessment of current pain intensity. Background data were gathered using a standardized interview. Examinations were conducted at physiotherapy premises by physiotherapists who were blinded to group allocation. Baseline and post-treatment examinations were performed by the same physiotherapists.

\section{Measures included in analyses}

The dependent variables followed by the independent variables included in the analyses of explanatory factors for improvement in the pain and disability are subsequently presented.

\section{Dependent variable \\ Pain disability}

The Pain Disability Index PDI was used to assess the impact that pain has on the ability of a person to participate in essential life activities on a scale from 0-70. A higher score indicates greater disability. The PDI includes seven subscales: (1) family and home responsibilities, covering activities related to home and family; (2) recreation, covering hobbies, sports and other leisure time activities; (3) social activity, covering participation with friends and acquaintances other than family members; (4) occupation, covering activities partly or directly related to working, including housework or volunteering; (5) sexual behavior, covering frequency and quality of sex life; (6) self care, covering personal maintenance and independent daily living (bathing, dressing, etc.); and (7) life-support activity, covering basic life-supporting behavior (eating, sleeping, breathing, etc.) [42, 43]. The PDI has shown satisfactory test-retest reliability and is valid for patients with chronic pain [42-44].

\section{Selection of independent variables}

Variables that were included as potential predictors or explanatory factors for change in the dependent outcome variables were as follows. Age and symptom duration were selected because older age could be anticipated to influence the effect of the resistance exercise and a longer symptom duration often means a prolonged period of decrease in the level of physical activity, which could potentially influence the level of disability.

\section{Pain intensity}

Pain intensity correlates with the degree of disability in FM [45], and it is reasonable to assume that change in pain intensity would influence the degree of disability. Current pain intensity was measured by a visual analog scale (VAS). A 100-mm plastic VAS with a moveable cursor along a line and anchors at the extremes only ("no pain at all" to "worst imaginable pain"), was used. The participant was asked to assess her current pain ranging from "no pain at all" to "worst imaginable pain". The VAS has been reported to be a useful measure of pain intensity in most settings [46].

\section{Muscle strength}

Muscle strength is reduced by $20-40 \%$ in FM, and previous studies have shown a correlation between muscle strength and disability in FM [45]. It was hypothesized that improved muscle strength might improve disability. Isometric knee-extension force $(\mathrm{N})$ was measured with a dynamometer (Steve Strong: Stig Starke HBI, Göteborg, 
Sweden) using a standard protocol. The participant was in a fixed seated position with back support, knee and hip in $90^{\circ}$ of flexion, and legs hanging freely. A nonelastic strap was placed around the ankle and attached to a pressure transducer with an amplifier. The subjects were instructed and verbally encouraged to pull the ankle strap with maximal force for 5 seconds. Three trials were performed for each test with a 1-minute rest between each trial. The best performance out of three trials was recorded.

Hand-grip force $(\mathrm{N})$ was registered bilaterally using Grippit $^{\oplus}$ (AB Detektor, Göteborg, Sweden). The mean force over 10 seconds was recorded [47]. Two trials were performed for each test with a 1-minute rest between each trial. The best performance out of two trials was recorded.

\section{Physical activity}

Exercise is considered to be an important part of rehabilitation in FM, and it was of interest to study if the amount of physical activity was related to disability. The leisure time physical activity instrument (LTPAI) was used to assess the amount of physical activity performed during a typical week, reported in hours. The total score is the sum of hours spent on the activities [48].

\section{Fear avoidance beliefs about physical activity}

The theoretical construct of fear avoidance is an interesting concept in exercise interventions, as fear of physical activity was hypothesized to change during the intervention as the participants confronted with their pain at each session, which is the opposite to avoiding pain. The fear avoidance beliefs questionnaire, physical subscale $\left(\mathrm{FABQ}_{\text {physical }}\right)$ was used to assess the extent to which fear and avoidance affect physical beliefs (four items, 0-24). A higher score represents more fear avoidance beliefs [49].

\section{Statistics}

Data were computerized and analyzed using the Statistical Package Software for the Social Sciences (SPSS version 22.0, Chicago, IL, USA). Descriptive data are presented as mean, standard deviation (SD), median (min; max) for continuous variables or the number $(n)$ and percentage (\%) for categorical variables. All significance tests were two-sided and conducted at the $5 \%$ significance level. Outcomes were analyzed according to the intention-to-treat design, implying that all participants were invited to post-treatment examination, whether they had participated in the intervention or not. Only measured values were included in analyses of changes over time, implying that cases missing were not included in the analysis. The Wilcoxon signed rank test was used to analyze changes from baseline to posttreatment examinations in the PDI total score and the PDI domains within the resistance exercise group.
Correlation between the dependent variables of change in pain disability and baseline measures and measures of change in the independent variables was tested by calculating the Spearman correlation coefficient. Variables with a $p$ value $<0.2$ on analysis of correlation were included in further analyses using multiple linear forward stepwise regression analysis. The assumptions of normality were confirmed by checking the residual scatter plots and histograms of each variable respectively. Linear forward stepwise multiple regression analysis was performed to analyze explanatory factors for improvements in and pain disability.

\section{Results}

Results reported elsewhere and used in this study Characteristics of participants

The mean age of the participants was 51 (SD 9.1) years $(\mathrm{n}=67)$. Their mean symptom duration was 11 (SD 8.5) years $(n=67)$. A total of $38(57 \%)$ women worked to some extent and 2 (3\%) were full-time students, while $22(34 \%)$ did not work due to sick leave and 5 (7\%) did not work due to unemployment.

\section{Pain disability}

Mean pain disability at baseline was 35.3 (SD 12.2) $(n=67)$. Participants rated significantly reduced pain disability $(p=0.006)$ at post-treatment examination compared to baseline $(\Delta-3.8, \mathrm{SD} 10.6)(\mathrm{n}=56)$ [37].

\section{Pain intensity}

The mean pain intensity at baseline was 49 (SD 23.9) $\mathrm{mm}$ $(\mathrm{n}=67)$. Pain intensity was significantly reduced $(p=0.002)$ from baseline to post-treatment examination $(\Delta-5.7$, SD 15.0) $(\mathrm{n}=56)$ [37].

\section{Muscle strength}

The mean isometric knee-extension force at baseline was 330 (SD 109.4) N ( $\mathrm{n}=67)$. Isometric knee-extension force improved significantly $(p=0.002)$ from baseline to post-treatment examination $(\Delta 30.4$, SD 71.9$) \quad(n=56)$ [37]. The mean hand-grip force at baseline was 162 (SD 68.7) N ( $\mathrm{n}=67)$. Hand-grip force improved significantly $(p<0.001)$ from baseline to post-treatment examination $(\Delta 20.1$, SD 36.1) $(\mathrm{n}=52)$ [37].

\section{Physical activity}

The mean amount of physical activity at baseline was 5.6 (SD 4.8) hours $(n=67)$. The amount of physical activity increased significantly $(p<0.001)$ from baseline to post-treatment examination $(\Delta 2.3$, SD 4.8) $(n=56)$ [37].

\section{Fear avoidance beliefs}

The mean fear avoidance beliefs about physical activity were 9.7 (SD 6.1) $(n=67)$. At the individual level, $23 \%$ 
(15 out of 67) of the women displayed elevated fear avoidance beliefs corresponding to a fear avoidance score of $>14$ [50] at baseline, and $17 \%$ (9 out of 54) displayed elevated fear avoidance beliefs at the posttreatment examination. Fear avoidance beliefs about physical activity did not improve significantly $(p=0.36)$ from baseline to post-treatment examination $(\Delta-0.8$, SD 7.0) $(\mathrm{n}=54)$ [37].

\section{Within-group analysis of change in pain disability}

The PDI total score and the domains of recreation, social activity and occupation improved significantly from baseline to post-treatment examinations (Table 1).

\section{Explanatory factors for reduced pain disability}

The results of the correlation analyses are presented in Table 2. Variables that were found to correlate with pain disability with a $p$ value $<0.2$ were included in the multiple linear regression analyses of explanatory factors for change in pain disability. The results of the regression analyses of explanatory factors are presented in Table 3 .

\section{Pain disability (PDI total)}

Higher pain disability at baseline together with improvement in fear avoidance beliefs about physical activity were found to partly explain improvement in pain disability. This model explained $28 \%$ of the improvement in pain disability $(p=0.005)$ (Table 3$)$.

Table 1 Analysis of change in pain disability from baseline to post-treatment examinations

\begin{tabular}{|c|c|c|c|}
\hline \multirow[t]{2}{*}{ Pain disability index (PDI) } & \multirow{2}{*}{$\begin{array}{l}\text { Baseline } \\
(n=67) \\
\text { Mean (SD) } \\
\text { Median } \\
\text { (min; max) }\end{array}$} & $\begin{array}{l}\text { Post-test- } \\
\text { baseline } \\
(n=56)\end{array}$ & \multirow{2}{*}{$\begin{array}{l}\text { Statistics } \\
P \text { value }\end{array}$} \\
\hline & & $\begin{array}{l}\Delta \text { Mean (SD) } \\
\text { Median } \\
\text { (min; max) }\end{array}$ & \\
\hline PDI total (0-70) & $\begin{array}{l}35.25(12.23) \\
36(8 ; 69)\end{array}$ & $\begin{array}{l}-3.84(10.56) \\
-4.5(-29 ; 23)\end{array}$ & 0.006 \\
\hline PDI family and home (0-10) & $\begin{array}{l}5.39(2.07) \\
6(1 ; 10)\end{array}$ & $\begin{array}{l}-0.38(2.32) \\
0(-6 ; 5)\end{array}$ & 0.24 \\
\hline PDI recreation $(0-10)$ & $\begin{array}{l}6.55(2.13) \\
7(1 ; 10)\end{array}$ & $\begin{array}{l}-0.91(2.11) \\
-1(-6 ; 4)\end{array}$ & 0.002 \\
\hline PDI social activity (0-10) & $\begin{array}{l}5.21(2.41) \\
5(1 ; 10)\end{array}$ & $\begin{array}{l}-0.70(2.31) \\
-0.5(-5 ; 5)\end{array}$ & 0.034 \\
\hline PDI occupation (0-10) & $\begin{array}{l}5.94(2.70) \\
7(1 ; 10)\end{array}$ & $\begin{array}{l}-0.59(2.35) \\
-0.5(-6 ; 7)\end{array}$ & 0.031 \\
\hline PDI sex life (0-10) & $\begin{array}{l}5.71(2.52) \\
6(1 ; 10)\end{array}$ & $\begin{array}{l}-0.46(2.20) \\
0(-8 ; 5)\end{array}$ & 0.156 \\
\hline PDI self care $(0-10)$ & $\begin{array}{l}3.36(2.25) \\
3(1 ; 9)\end{array}$ & $\begin{array}{l}-0.45(1.88) \\
0(-6 ; 5)\end{array}$ & 0.071 \\
\hline PDI life-support activity (0-10) & $\begin{array}{l}3.16(2.52) \\
2(1 ; 10)\end{array}$ & $\begin{array}{l}-0.59(2.92) \\
0(-8 ; 6)\end{array}$ & 0.10 \\
\hline
\end{tabular}

Missing values: PDI sex life $(n=2) . \Delta$ refers to change between post-test and baseline values. $P$ values in bold type were significant

\section{PDI recreation}

Improvement in fear avoidance beliefs about physical activity together with higher baseline values of PDI recreation were found to partly explain improvement in PDI recreation. This model explained $32 \%$ of the improvement in PDI recreation $(p<0.025)$ (Table 3$)$.

\section{PDI social activity}

Higher baseline values of PDI social activity together with improvement in fear avoidance beliefs about physical activity were found to partly explain improvement in PDI social activity. This model explained $30 \%$ of the improvement in PDI social activity $(p<0.017)$ (Table 3$)$.

\section{PDI occupation}

Higher baseline values of PDI occupation were found to partly predict the improvement in PDI occupation. This model predicted $19 \%$ of the improvement in PDI occupation $(p=0.001)$ (Table 3$)$.

\section{Discussion}

The pain disability total score and three out of the total of seven domains of pain disability improved with resistance exercise, the improved domains being recreation, social activity, and occupation. These domains are regarded as activities that require more physical capacity, which was reflected by the baseline scores of these domains being higher compared to the baseline scores of the domains of self-care and life support activities, which can be regarded as less physically demanding activities [43]. The less physically demanding activities did not improve with resistance exercise, implying that the women had sufficient capacity for performing these activities to start with, and therefore the performance was not influenced by resistance exercise. The mean score for pain disability at baseline was $35.3(0-70)$, which is in line with recently published reference values for disability scores (PDI) in patients with chronic musculoskeletal pain [51]. A total of $54 \%(n=30)$ of the participants improved their pain disability by more than $12 \%$ from baseline to post-treatment examinations, which corresponds to a clinically relevant improvement in pain disability [52].

Occupational disability improved significantly with resistance exercise, which is an important result for most women with FM who are lacking sufficient physical capacity to perform their work tasks and facing the risk of long-term work disability [53, 54]. This improvement could contribute to future return to work among the women currently on sick leave or decreased risk of future sick leave among the women currently working. However, return to work is a complex process and no significant changes in actual sick leave were observed. 
Table 2 Analyses of correlations between the changes in pain disability and the independent variables $(n=56)$

\begin{tabular}{|c|c|c|c|c|}
\hline Independent variables & $\begin{array}{l}\Delta \text { PDI total } \\
r_{s}(p \text { value })\end{array}$ & $\begin{array}{l}\Delta P D \mid \text { recreation } \\
r_{s}(p \text { value })\end{array}$ & $\begin{array}{l}\Delta \text { PDI social } \\
r_{s}(p \text { value })\end{array}$ & $\begin{array}{l}\Delta \text { PDI occupation } \\
r_{\mathrm{s}}(p \text { value })\end{array}$ \\
\hline Age (years) & $0.16(0.23)$ & $0.05(0.74)$ & $-0.02(0.88)$ & $0.17(0.21)$ \\
\hline Symptom duration (years) & $0.03(0.81)$ & $-0.12(0.37)$ & $0.12(0.37)$ & $0.17(0.22)$ \\
\hline Pain intensity (0-100) & $-0.26(0.054)^{a}$ & $-0.19(0.17)^{a}$ & $-0.04(0.75)$ & $-0.06(0.67)^{a}$ \\
\hline PDI total (0-70) & $-0.34(0.01)$ & $-0.25(0.066)^{a}$ & $-0.25(0.067)^{a}$ & $-0.18(0.19)^{a}$ \\
\hline PDI recreation (0-10) & - & $-0.30(0.027)$ & - & - \\
\hline PDI social (0-10) & - & - & $-0.45(<0.001)$ & - \\
\hline PDI occupation (0-10) & - & - & - & $-0.37(0.005)$ \\
\hline LTPAI (hours) & $0.19(0.17)^{a}$ & $0.09(0.54)$ & $0.04(0.75)$ & $-0.01(0.99)$ \\
\hline Knee-extension force $(\mathrm{N})$ & $-0.13(0.32)$ & $0.04(0.75)$ & $-0.07(0.61)$ & $-0.15(0.28)$ \\
\hline Hand-grip force (N) & $-0.05(0.70)$ & $0.11(0.43)$ & $-0.01(0.99)$ & $-0.061(0.65)$ \\
\hline$F A B Q_{\text {physical }}(0-24)$ & $0.01(0.93)$ & $0.04(0.75)$ & $-0.18(0.19)^{a}$ & $0.01(0.94)$ \\
\hline$\Delta$ Pain intensity (0-100) & $0.36(0.008)$ & $0.35(0.008)$ & $0.18(0.19)^{\mathrm{a}}$ & $0.15(0.26)$ \\
\hline$\Delta$ LTPAI (hours) & $-0.28(0.037)$ & $-0.11(0.43)$ & $-0.27(0.049)$ & $-0.05(0.72)$ \\
\hline$\Delta$ Knee-extension force $(\mathrm{N})$ & $-0.32(0.019)$ & $-0.16(0.25)$ & $-0.12(0.39)$ & $-0.23(0.09)$ \\
\hline$\Delta$ Hand-grip force $(\mathrm{N})$ & $-0.23(0.10)^{\mathrm{a}}$ & $-0.14(0.33)$ & $-0.25(0.08)$ & $-0.32(0.023)$ \\
\hline$\Delta F A B Q_{\text {physical }}(0-24)$ & $0.36(0.007)$ & $0.44(0.001)$ & $0.34(0.012)$ & $0.17(0.23)$ \\
\hline
\end{tabular}

Missing values: fear avoidance beliefs questionnaire $(F A B Q)_{\text {physical }}(n=1), \Delta F A B Q_{\text {physical }}(n=2), \Delta$ pain disability index $(P D I)$ social $(n=2), \Delta P D I$ occupation $(n=2)$, $\Delta$ Hand-grip force $(n=4): \Delta$ refers to change between post-test and baseline values. LTPAl, leisure time physical activity instrument. Results for variables with a

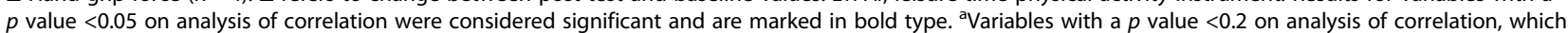
were then included in multiple stepwise regression analysis

The only variable that explained improvement in pain disability due to resistance exercise was decrease in fear avoidance beliefs about physical activity, besides higher baseline values of pain disability, which was expected. The results imply that fear avoidance beliefs are an important factor to take into consideration, and strategies to diminish fear while performing physical exercise need to be included in an exercise program. However, the models only explain $19-32 \%$ of the improvement in pain disability, implying that other unknown factors also contribute to the change.

Table 3 Explanatory models for improvement in pain disability $(n=56)$

\begin{tabular}{|c|c|c|c|c|}
\hline \multirow{2}{*}{\multicolumn{2}{|c|}{ Explanatory model for change in pain disability }} & \multirow[t]{2}{*}{$R$ square } & Unstandardized coefficients & \multirow[t]{2}{*}{$P$ value } \\
\hline & & & B (Std error) & \\
\hline 1 & $\Delta F A B Q_{\text {physical }}$ & \multirow[t]{2}{*}{0.28} & $0.52(0.18)$ & 0.006 \\
\hline 2 & PDI total & & $-0.32(0.11)$ & 0.005 \\
\hline \multirow{2}{*}{\multicolumn{2}{|c|}{ Explanatory model for change in PDI recreation }} & \multirow[t]{2}{*}{$R$ square } & Unstandardized coefficients & \multirow[t]{2}{*}{$P$ value } \\
\hline & & & B (Std error) & \\
\hline 1 & $\Delta F A B Q_{\text {physical }}$ & \multirow[t]{2}{*}{0.32} & $0.13(0.04)$ & 0.001 \\
\hline 2 & PDI recreation & & $-0.28(0.12)$ & 0.025 \\
\hline \multirow{2}{*}{\multicolumn{2}{|c|}{ Explanatory model for change in PDI social activity }} & \multirow[t]{2}{*}{$R$ square } & Unstandardized coefficients & \multirow[t]{2}{*}{$P$ value } \\
\hline & & & B (Std error) & \\
\hline 1 & PDI social & \multirow[t]{2}{*}{0.30} & $-0.42(0.11)$ & $<0.001$ \\
\hline 2 & $\Delta F A B Q_{\text {physical }}$ & & $0.10(0.04)$ & 0.017 \\
\hline \multirow{2}{*}{\multicolumn{2}{|c|}{ Explanatory model for change in PDI occupation }} & \multirow[t]{2}{*}{$R$ square } & Unstandardized coefficients & \multirow[t]{2}{*}{$P$ value } \\
\hline & & & B (Std error) & \\
\hline 1 & PDI occupation & 0.19 & $-0.38(0.11)$ & 0.001 \\
\hline
\end{tabular}

Missing values: regression model for change in pain disability $(n=2)$, regression model for change in pain disability index $(P D I)$ recreation $(n=2)$, regression model for change in PDI social activity $(n=2)$, regression model for change in PDI occupation $(n=2)$. $\Delta$ refers to change between post-test and baseline values. $F A B Q_{\text {physical }}$ fear avoidance beliefs questionnaire, physical subscale, Std error standard error 
The primary reason for the graded progression of loads in the individualized resistance exercise program was to avoid exercise-induced pain. However, from a fear avoidance perspective, the progression seems to also have worked as a graded exposure to physical activity, which has previously been reported to reduce fear avoidance beliefs in patients with FM [55].

Fear avoidance beliefs about physical activity did not, however, improve significantly in the women participating in the resistance exercise program, as reported in our previous RCT [37]. One reason as to why the fear avoidance beliefs did not improve significantly with resistance exercise might be that the levels of fear avoidance were relatively low at baseline, mean 9.71, SD 6.08, on a scale ranging from 0-24 [49]. The cutoff score for elevated fear avoidance beliefs in physical activity have previously been defined as $>14(0-24)$ [50]. When comparing the levels of fear avoidance beliefs of the participants in our study at the individual level with this cutoff we found that the baseline scores of $23 \%$ of the women in our study population corresponded to elevated fear avoidance beliefs, while the percentage was $17 \%$ at post-treatment examinations.

The improvement in pain disability due to resistance exercise can be assumed to be related to improvement in physical capacity and the participants becoming increasingly motivated to exercise with heavy loads. This process was facilitated by the person-centered approach [41] of the intervention, based on principles of increasing selfefficacy [56]. To give the participant a sense of control in a given situation is an important component to enhance self-efficacy and this was achieved by the active involvement of the participant in adjusting and modifying the exercises and loads and in the progression of the resistance exercise [57]. The exercise was initiated at low loads during an extended time period, to allow for a positive experience of the exercise and a slow adaptation of the participants' physical capacity to avoid exercise-induced pain. Performing the exercise program in small groups together with others sharing similar difficulties and to see them manage the exercise is another of the key components of self-efficacy enhancement [56], and hence, it is beneficial for persons with FM to exercise in groups. Also, encouragement and physiological feedback from physiotherapists supervising the groups is assumed to support self-efficacy to manage disabilities while exercising [56].

The fact that age, symptom duration, pain intensity, and muscle strength at baseline had no explanatory value for reduced pain disability indicates that the effects of this resistance exercise program did not depend on the characteristics of each individual participant, but rather that the intervention has the potential to be effective for anyone with FM, who is interested in exercise, which was the idea when assuming a person-centered approach to the intervention.

\section{Limitations}

The recruitment procedure i.e., newspaper advertisement may have resulted in recruitment of participants who were motivated to exercise and this could bias the results. To minimize this risk the advert was designed to recruit participants to both interventions so none of the participants would know in advance which intervention was the active intervention or the control intervention.

\section{Conclusions}

The person-centered resistance exercise intervention, based on principles of self-efficacy, had a positive effect on recreational, social, and occupational disability. The reduced pain disability appeared to be mediated by decrease in fear avoidance beliefs together with higher baseline scores for pain disability; however, these results are exploratory and need replication.

\section{Abbreviations}

FABQ: fear avoidance beliefs questionnaire; $F A B Q_{\text {physical: fear avoidance }}$ beliefs questionnaire, physical subscale; FM: fibromyalgia; LTPAI: leisure time physical activity instrument; PDI: pain disability index; RCT: randomized controlled trial; RM: repetition maximum; VAS: visual analog scale.

\section{Competing interests}

The authors declare that they have no competing interests.

\section{Authors' contributions}

The authors of this multicenter study have contributed as follows and their research site is also specified: AP (Gothenburg site) worked with study design, data analysis, interpretation of data, and the first draft of the manuscript. AL worked with study design and data analysis; ML (Stockholm site) worked with acquisition; ME (Stockholm site) participated in study conception and study design; JB (Gothenburg site) worked with acquisition and interpretation of data; IB-L (Stockholm site) participated in study design and acquisition; BG (Linköping site) worked with study conception, study design, and acquisition; EK (Stockholm site) worked with study conception, study design, and acquisition; KM (Gothenburg site) worked with study conception, study design, acquisition, analysis, and interpretation of data. All the authors were involved in writing the manuscript and revising it critically for important intellectual content. All the authors approved the final version of the article.

\section{Acknowledgements}

The study was supported by the Swedish Rheumatism Association, the Swedish Research Council, the Health and Medical Care Executive Board of Västra

Götaland Region, ALF-LUA at Sahlgrenska University Hospital, Stockholm County Council (ALF), the Renée Eander foundation, The Norrbacka Eugenia foundation, and Gothenburg Center for Person Centered Care (GPCC), FA insurance.

\section{Author details}

${ }^{1}$ Institute of neuroscience and physiology, Sahlgrenska Academy, University of Gothenburg, Gothenburg, Sweden. ${ }^{2}$ University of Gothenburg Centre for Person Centered Care (GPCC), Gothenburg, Sweden. ${ }^{3}$ Dep of Clinical

Sciences, Karolinska Institutet and Dep of Rehabilitation Medicine, Danderyd Hospital, Stockholm, Sweden. ${ }^{4}$ Department of Dental Medicine, Karolinska Institutet, and Scandinavian Center for Orofacial Neurosciences (SCON), Huddinge SE-141 04, Sweden. ${ }^{5}$ Sahlgrenska University Hospital, Rheumatology, Göteborg, Sweden. ${ }^{6}$ Department of Medical and Health Sciences, Faculty of Medicine and Health Sciences, Linköping University, Pain and Rehabilitation Centre, Linköping, Sweden. ${ }^{7}$ Department of Medical and Health Sciences, Linköping University, Linköping, Sweden. ${ }^{8}$ Department of Clinical Neuroscience, Karolinska Institutet and Stockholm Spine Center, Stockholm, Sweden. 


\section{Received: 22 December 2015 Accepted: 28 April 2016}

\section{Published online: 21 May 2016}

\section{References}

1. World Health Organization. ICF: International Classification of Functioning, Disability and Health. Geneva: WHO; 2001

2. Kivimäki M, Ferrie JE, Hagberg J, Head J, Westerlund H, Vahtera J, et al. Diagnosis-specific sick leave as a risk marker for disability pension in a Swedish population. J Epidemiol Community Health. 2007;61(10):915-20.

3. The Social Insurance Agency. Social Insurance Report 2011;4. https://www. forsakringskassan.se/statistik/publikationer/socialforsakringsrapporter.

4. Annemans L, Lay KL, Taïeb C. Societal and patient burden of fibromyalgia syndrome. Pharmacoeconomics. 2009;27(7):547-59. doi:10.2165/11313650-000000000-00000.

5. Fjell $Y$, Alexanderson $K$, Karlqvist L, Bildt C. Self-reported musculoskeletal pain and working conditions among employees in the Swedish public sector. Work. 2007;28(1):33-46.

6. Persson J, Bernfort L, Wåhlin C, Öberg B, Ekberg K. Costs of production loss and primary health care interventions for return-to-work of sick-listed workers in Sweden. Disabil Rehabil. 2015;37(9):1-6

7. Gran JT. The epidemiology of chronic generalized musculoskeletal pain. Best Pract Res Clin Rheumatol. 2003;17(4):547-61.

8. Lindell L, Bergman S, Petersson IF, Jacobsson LTH, Herrström P. Prevalence of fibromyalgia and chronic widespread pain. Scand J Prim Health Care. 2000;18:149-53.

9. Wolfe F, Ross K, Anderson J, Russell IJ, Hebert L. The prevalence and characteristics of fibromyalgia in the general population. Arthritis Rheum. 1995:38:19-28

10. Wolfe F, Smythe HA, Yunus MB, Bennett RM, Bombardier C, Goldenberg DL, et al. The American College of Rheumatology 1990 criteria for the classification of fibromyalgia. Report of the Multicenter Criteria Committee. Arthritis Rheum. 1990;33:160-72.

11. Góes SM, Leite N, Shay BL, Homann D, Stefanello JM, Rodacki AL. Functional capacity, muscle strength and falls in women with fibromyalgia. Clin Biomech. 2012;27(6):578-83.

12. Henriksen $M$, Lund $H$, Christensen $R$, Jespersen $A$, Dreyer L, Bennett RM, et al. Relationships between the fibromyalgia impact questionnaire, tender point count, and muscle strength in female patients with fibromyalgia: a cohort study. Arthritis Care Res. 2009;61(6):732-9.

13. Mannerkorpi K, Burchkardt CS, Bjelle A. Physical performance characteristics of women with fibromyalgia. Arthritis Care Res. 1994;7:123-9.

14. Palstam A, Larsson A, Bjersing J, Löfgren M, Ernberg M, Bileviciute-Ljungar I, et al. Perceived exertion at work in women with fibromyalgia: explanatory factors and comparison with healthy women. J Rehabil Med. 2014;46(8):773-80.

15. Jones J, Rutledge DN, Jones KD, Matallana L, Rooks DS. Self-assessed physical function levels of women with fibromyalgia: a national survey. Women's Health Issues. 2008:18(5):406-12.

16. Henriksson C, Burckhardt C. Impact of fibromyalgia on everyday life: a study of women in the USA and Sweden. Disabil Rehabil. 1996;18(5):241-8.

17. McDonald M, Di Bonaventura M, Ullman S. Musculoskeletal pain in the workforce: the effects of back, arthritis, and fibromyalgia pain on quality of life and work productivity. J Occup Environ Med. 2011;53(7):765-70.

18. White KP, Speechley M, Harth M, Ostbye T. Comparing self-reported function and work disability in 100 community cases of fibromyalgia syndrome versus controls in London, Ontario: The London fibromyalgia epidemiology study. Arthritis Rheum. 1999:42(1):76-83. doi:10.1002/ 1529-0131(199901)42:1<76::aid-anr10>3.0.co;2-g.

19. Burckhardt CS, Liedberg GM, Henriksson CM, Kendall S. The impact of fibromyalgia on employment status of newly-diagnosed young women: a pilot study. J Musculoskelatal Pain. 2005;13(2):31-41.

20. Henriksson C, Liedberg G. Factors of importance for work disability in women with fibromyalgia. J Rheumatol. 2000;27(5):1271-6.

21. Palstam A, Bjersing $J L$, Mannerkorpi K. Which aspects of health differ between working and nonworking women with fibromyalgia? A cross-sectional study of work status and health. BMC Public Health. 2012;12(1):1076.

22. Holtermann A, Hansen JV, Burr H, Søgaard K. Prognostic factors for long-term sickness absence among employees with neck-shoulder and low-back pain. Scand J Work Environ Health. 2010;36(1):34.

23. Kärkkäinen S, Pitkäniemi J, Silventoinen K, Svedberg P, Huunan-Seppälä A Koskenvuo K, et al. Disability pension due to musculoskeletal diagnoses: importance of work-related factors in a prospective cohort study of Finnish twins. Scand J Work Environ Health. 2013;39(4):343-50.

24. Mannerkorpi K, Gard G. Hinders for continued work among persons with fibromyalgia. BMC Musculoskelet Disord. 2012;13(1):96. doi:10.1186/1471-2474-13-96.

25. McLoughlin MJ, Colbert LH, Stegner AJ, Cook DB. Are women with fibromyalgia less physically active than healthy women. Med Sci Sports Exerc. 2011;43(5):905-12.

26. Elvin A, Siösteen AK, Nilsson A, Kosek E. Decreased muscle blood flow in fibromyalgia patients during standardised muscle exercise: a contrast media enhanced colour Doppler study. Eur J Pain. 2006;10(2):137-44.

27. van Santen M, Bolwijn P, Verstappen F, Bakker C, Hidding A, Houben $\mathrm{H}$, et al. A randomized clinical trial comparing fitness and biofeedback training versus basic treatment in patients with fibromyalgia. J Rheumatol. 2002;29(3):575-81.

28. Leeuw M, Goossens ME, Linton SJ, Crombez G, Boersma K, Vlaeyen JW. The fear-avoidance model of musculoskeletal pain: current state of scientific evidence. J Behav Med. 2007:30(1):77-94.

29. Winkelmann A, Häuser W, Friedel E, Moog-Egan M, Seeger D, Settan M, et al. Physiotherapy and physical agent therapies for fibromyalgia syndrome, Systematic review, meta-analysis and guidelines. Schmerz. 2012;26(3):276-86. doi:10.1007/s00482-012-1171-3.

30. Carville SF, Arendt-Nielsen S, Bliddal H, Blotman F, Branco JC, Buskila D, et al. EULAR evidence-based recommendations for the management of fibromyalgia syndrome. Ann Rheum Dis. 2008;67(4):536-41. doi:10.1136/ ard.2007.071522

31. Fitzcharles M-A, Ste-Marie PA, Goldenberg DL, Pereira JX, Abbey S, Choinière M, et al. 2012 Canadian guidelines for the diagnosis and management of fibromyalgia syndrome: executive summary. Pain Res Manag. 2013;18(3):119.

32. Bernhardsson. S, Ericsson. A, Karlsson. M, Larsson. M, Mannerkorpi. K, Nordeman. L. Fysioterapeutisk behandlingsriktlinje för fibromyalgi. Västra Götalandsregionen, Sweden; 2014.

33. Kosek E, Löfgren M. Regionalt vårdprogram fibromyalgi, Stockholms läns landsting. Stockholm, Sweden; 2009.

34. Häkkinen A, Häkkinen K, Hannonen P, Alen M. Strength training induced adaptations in neuromuscular function of premenopausal women with fibromyalgia: comparison with healthy women. Ann Rheum Dis. 2001;60(1):21-6.

35. Valkeinen $\mathrm{H}$, Häkkinen $\mathrm{A}$, Hannonen $\mathrm{P}$, Häkkinen $\mathrm{K}$, Alén M. Acute heavyresistance exercise-induced pain and neuromuscular fatigue in elderly women with fibromyalgia and in healthy controls: effects of strength training. Arthritis Rheum. 2006;54(4):1334-9.

36. Jones KD, Burckhardt CS, Clark SR, Bennett RM, Potempa KM. A randomized controlled trial of muscle strengthening versus flexibility training in fibromyalgia. J Rheumatol. 2002;29(5):1041-8.

37. Larsson A, Palstam AL, Löfgren M, Ernberg M, Bjersing J, Bileviciute-Ljungar I, et al. Resistance exercise improves muscle strength, health status and pain intensity in fibromyalgia - a randomized controlled trial. Arthritis Res Ther. 2015;17(1):1-15.

38. Busch AJ, Webber SC, Richards RS, Bidonde J, Schachter CL, Schafer LA, et al. Resistance exercise training for fibromyalgia. Cochrane Database Syst Rev. 2013;12, CD010884. doi:10.1002/14651858.CD010884.

39. Bircan C, Karasel SA, Akgun B, El O, Alper S. Effects of muscle strengthening versus aerobic exercise program in fibromyalgia. Rheumatol Int. 2008;28(6):527-32. doi:10.1007/s00296-007-0484-5.

40. Kayo AH, Peccin MS, Sanches CM, Trevisani VF. Effectiveness of physical activity in reducing pain in patients with fibromyalgia: a blinded randomized clinical trial. Rheumatol Int. 2011. doi:10.1007/s00296-011-1958-z.

41. Ekman I, Swedberg K, Taft C, Lindseth A, Norberg A, Brink E, et al. Personcentered care-Ready for prime time. Eur J Cardiovasc Nurs. 2011;10(4):248-51.

42. Tait RC, Pollard CA, Margolis RB, Duckro PN, Krause SJ. The pain disability index: psychometric and validity data. Arch Phys Med Rehabil. 1987:68(7):438-41.

43. Tait RC, Chibnall JT, Krause S. The pain disability index: psychometric properties. Pain. 1990;40(2):171-82.

44. Grönblad M, Hupli M, Wennerstrand P, Järvinen E, Lukinmaa A, Kouri J-P, et al. Intel-correlation and test-retest reliability of the pain disability index (PDI) and the Oswestry disability questionnaire (ODQ) and their correlation with pain intensity in low back pain patients. Clin J Pain. 1993;9(3):189-95.

45. Mannerkorpi K, Svantesson U, Broberg C. Relationships between performance-based tests and patients' ratings of activity limitations, selfefficacy, and pain in fibromyalgia. Arch Phys Med Rehabil. 2006;87(2):259. 
46. Hjermstad MJ, Fayers PM, Haugen DF, Caraceni A, Hanks GW, Loge JH, et al. Studies comparing numerical rating scales, verbal rating scales, and visual analogue scales for assessment of pain intensity in adults: a systematic literature review. J Pain Symptom Manage. 2011;41(6):1073-93.

47. Nordenskiold UM, Grimby G. Grip force in patients with rheumatoid arthritis and fibromyalgia and in healthy subjects. A study with the Grippit instrument. Scand J Rheumatol. 1993;22(1):14-9.

48. Mannerkorpi $\mathrm{K}$, Hernelid C. Leisure time physical activity instrument and physical activity at home and work instrument. development, face validity, construct validity and test-retest reliability for subjects with fibromyalgia. Disabil Rehabil. 2005;27(12):695-701. doi:10.1080/09638280400009063.

49. Waddell G, Newton M, Henderson I, Somerville D, Main CJ. A fear-avoidance beliefs questionnaire ( $\mathrm{FABQ}$ ) and the role of fear-avoidance beliefs in chronic low back pain and disability. Pain. 1993;52(2):157-68.

50. Burton AK, Waddell G, Tillotson KM, Summerton N. Information and advice to patients with back pain can have a positive effect: a randomized controlled trial of a novel educational booklet in primary care. Spine. 1999;24(23):2484

51. Soer R, Köke AJ, Speijer BL, Vroomen PC, Smeets RJ, Coppes MH, et al. Reference values of the pain disability index in patients with painful musculoskeletal and spinal disorders: a cross-national study. Spine. 2015:40(9):E545-51.

52. Soer R, Reneman MF, Vroomen PC, Stegeman P, Coppes MH. Responsiveness and minimal clinically important change of the pain disability index in patients with chronic back pain. Spine. 2012;37(8):711-5.

53. Andersen L, Clausen $T$, Persson R, Holtermann A. Dose-response relation between perceived physical exertion during healthcare work and risk of long-term sickness absence. Scand J Work Environ Health. 2012;38(6):582-89

54. Lötters F, Burdorf A. Prognostic factors for duration of sickness absence due to musculoskeletal disorders. Clin J Pain. 2006;22(2):212-21.

55. Van Koulil S, Kraaimaat F, van Lankveld W, Van Helmond T, Vedder A, Van Hoorn $\mathrm{H}$, et al. Cognitive-behavioral mechanisms in a pain-avoidance and a pain-persistence treatment for high-risk fibromyalgia patients. Arthritis Care Res. 2011;63(6):800-7.

56. Bandura A. Self-efficacy. New York: Wiley Online Library; 1994.

57. Holman H, Lorig K. Patient self-management: a key to effectiveness and efficiency in care of chronic disease. Public Health Rep. 2004;119(3):239.

\section{Submit your next manuscript to BioMed Central and we will help you at every step:}

- We accept pre-submission inquiries

- Our selector tool helps you to find the most relevant journal

- We provide round the clock customer support

- Convenient online submission

- Thorough peer review

- Inclusion in PubMed and all major indexing services

- Maximum visibility for your research

Submit your manuscript at www.biomedcentral.com/submit

) Biomed Central 